\title{
A Study on the Development of Cultural Tourism Resources in Hometown of Wang Anshi

\author{
XIONG Wen-ping
}

Nanchang Normal University, Nanchang Jiangxi, China, 330029

Icshxwp@126.com

Key words: Wang Anshi, hometown, cultural tourism, resource development

\begin{abstract}
Wang Anshi enjoys worldwide reputation and Fuzhou City is his hometown. Fuzhou should rely on the cultural brand of Wang Anshi and integrate tourist resources in Fuzhou to establish itself into a cultural tourism area of Wang Anshi's hometown, thus transferring the advantage of cultural tourism into one of tourism economy. On the basis of elaborating the importance, favorable conditions and problems of developing cultural tourism resources in the hometown of Wang Anshi, the paper raises thoughts and measures of such development.
\end{abstract}

\section{Favorable factors for cultural tourism resources development in the hometown of Wang Anshi}

1. Ideal basic conditions. Firstly, Fuzhou features rich resources of cultural tourism of striking characteristics. Boasting a good eco-environment, Fuzhou City in Jiangxi Province has been honored as "National Forest City" and "China's Oxygen Bar", holding renowned mountains like Dajue Mountain, Magu Mountain and Junfeng Mountain, and home to celebrities and scholars, such as Wang Anshi, "Chinese reformer of the $11^{\text {th }}$ Century"; Tang Xianzu, "Chinese master playwright" and "Oriental Shakespeare"; Zeng Gong among "Top Eight Scholars of Tang and Song Dynasties"; and Lu Jiuyuan, the master of the philosophy of mind. Also, Fuzhou is famous for its high quality basic educations, with its famous schools Linchuan No.1 High School, Linchuan No.2 High School and Fuzhou No.1 High School sending many students of best universities in China, including Peking University and Tsinghua University. Fuzhou is characterized by abundant resources of crops, with its Nanfeng orange, Guangchang white lotus and Linchuan watermelon enjoying nationwide reputation. There're also ancient villages and towns like Liukeng and Yaoxi in Fuzhou. The operas created by Tang Xianzu are very popular abroad, and Linchuan tea-picking opera, Yihuang opera, Nanfeng exorcising dance and Le'an exorcising dance have been listed as National Intangible Cultural Heritage. Gathering celebrities, beautiful mountains, renowned products, ancient villages and profound operas, Fuzhou thus integrates natural landscapes, Linchuan culture and modern civilization, having high level and taste of resources like the hometown of Tang Xianzu, beauty of Dajue Mountain, thousand-year ancient village of Liukeng, hometown of scholars and tasty Nanfeng orange. All these rich cultural resources in Fuzhou have become the advantages for Fuzhou's development of cultural tourism. It's worth mentioning that Wang Anshi born in Fuzhou City of Jiangxi Province was honored "Chinese reformer of the $11^{\text {th }}$ Century"; he's not only famous around the world but has been highly praised with his integrity and personality, thus making a branded and featured resource for cultural tourism in Fuzhou. Secondly, Fuzhou has an evident strength in regional joint development. Neighboring Nanchang, Fuzhou sees its downtown area and Dongxiang County included into the metropolitan area of Nanchang, and Fuzhou will strive to build up an exemplary cooperation zone with Nanchang to march toward Nanchang-Fuzhou Integration. The completion of Nanchang-Fuzhou Expressway and Xiangtang-Putian Expressway has strengthened the traffic interconnection between Fuzhou and Nanchang and the ecological cultural tourism circle of Fujian and Zhejiang, so that the tourist traffic conditions in Fuzhou has been largely promoted to enhance its tourist accessibility. Thirdly, cultural tourism development in Fuzhou has seen primary achievements. With its strategy of "prospering the city by cultural tourism" 
aimed to boost the development of cultural tourism, Fuzhou has also acquired some fruits in cultural tourism projects like tourist attractions, tourist hotels, traveler's malls and tourism traffic. Fuzhou Hall of Fame, Dream Garden and Dream Lake have been recognized as National 4A Scenic Spot, and Tang Xianzu Memorial and Nixian Platform after rebuilding have started to receive tourists, thus laying a solid foundation for cultural tourism development in Fuzhou.

2. Favorable development opportunities. Firstly, the building of cultural tourism area in Fuzhou. Fuzhou should seize the opportunities of building Urban Agglomeration in Middle Reaches of the Yangtze River and Poyang Lake Eco-economy Development Zone to establish a tourist area centered at downtown Fuzhou, led by Dajue Mountain and supported by hometown of Wang Anshi, Liukeng Village of Le'an and Celebrities' Sculpture Garden, so as to make the area a cultural tourism destination of outstanding characteristics and strong competitiveness. Secondly, the building of Nanchang-Fuzhou Integration. Fuzhou and Nanchang will co-build an exemplary cooperation zone and get included in Xiangtang-Putian Railway Economic Belt, for which tourism development is an important part. Its strength of tourism infrastructure and ability of tourism resources building will be strengthened, and the six elements concerning cultural tourism industry in Fuzhou will be highly improved. Thirdly, its presence in six national strategies. Fuzhou has been included in six national strategies, including Urban Agglomeration in Middle Reaches of the Yangtze River, Poyang Lake Eco-economy Development Zone, Southern Jiangxi Revival Plan and State-level Eco-demonstration Area (Jiangxi), hence distinct advantage of superposition of regional strategies. Being included in national strategy, Fuzhou is embracing the new situation of integrated resources development and joint regional development so that it's entering the period of strategic opportunities for major developing of cultural tourism industry.

\section{Existing problems in cultural tourism resources development in the hometown of Wang Anshi}

1. Despite more and more cultural projects in the hometown of Wang Anshi, the level of cultural tourism industrialization is relatively low. In recent years, due to heightened understanding of Fuzhou Government about the industry of cultural tourism, a group of projects of cultural tourism have been completed, including Fuzhou Hall of Fame, Dream Lake, Nixian Platform, Wang Anshi Memorial and Tang Xianzu Grand Theatre, and there're still some under planning. However, judging from the level of cultural industrialization in Fuzhou, the industrial chain of cultural tourism in Fuzhou is too weak with incomplete supporting facilities, initial development of cultural tourism and unsatisfactory integration of cultural elements into tourism, so that the profound connotation of Linchuan Culture was not fully utilized to boost cultural tourism projects in Fuzhou and there's no participatory and interactive cultural tourism products widely popular with tourists, thus the industrial chain is not well formed. The needs of dining, lodging, traffic, sightseeing and shopping are not fully considered to promote restaurants, hotels and products of relevant theme cultures, and the integration between natural ecological landscapes and cultural landscapes is low. In a nutshell, a comprehensive industrial chain of Fuzhou cultural tourism hasn't been formed to integrate functions and services like business, relaxation, meeting, culture, sightseeing, dining, fitness, healthcare, study, worship, shopping and holiday spending, so that the low industrialization makes it hard to keep tourists there for a longer time.

2. Despite the wide influence of the culture in Wang Anshi's hometown, the publicity and marketing of cultural tourism are weak. Fuzhou boasts many celebrities having wide influence in China and the rest of the world. They are: Wang Anshi, Chinese reformer of the $11^{\text {th }}$ Century and one of the Top Eight Scholars of Tang and Song Dynasties; Tang Xianzu, known to be Oriental Shakespeare and Chinese master playwright; Zeng Gong, also one of the Top Eight Scholars of Tang and Song Dynasties; Lu Jiuyuan, the master of the philosophy of mind; Shu Tong the calligrapher; Li Jingquan the revolutionist. Despite a lot of celebrities there and cultural profundity, its marketing lacks momentum. Though the era of all-round media marketing has set in, the ways of marketing and publicity of cultural tourism brands in Fuzhou are void of innovation, and there's no 
combined force in this connection, so that it's hard for independent brands to generate a fad of tourist consumption and strong competitive force without intensive publicity by brands integrated.

3. The hometown of Wang Anshi has no abundant products of cultural tourism, short of quality products and characteristics. The products of cultural tourism in Fuzhou are monotonous, mainly sightseeing products, so that it's still at the stage of extensive and shallow development. Short of participatory, entertaining, sightseeing and relaxing tourist products, Fuzhou rids tourists of rich experiencing and joy of relaxation during travel. Also, tourism development there is not well combined with industries of cartoon, sports, convention and exhibition, film and TV and cultural creativity, so that explicit difficulties in cultural tourism cannot be tackled. During development of cultural tourism in Fuzhou, routes of cultural tourism, quality products of cultural tourism, cultural tourism goods of Fuzhou characteristics cannot be developed and elite tourist products are absent: all these make it hard to promote the value and taste of cultural tourism products in Fuzhou and lead to insufficient competitiveness and attraction.

\section{Thoughts and measures of cultural tourism resources development in the hometown of Wang Anshi}

Analysis in the paper will show that the development of cultural tourism resources in the hometown of Wang Anshi should follow such an idea: seizing the opportunity of building historical and cultural city and ecological and cultural tourist area in Fuzhou and making Wang Anshi Culture the feature, integrating culture with tourism and seeking regional joint development, thus establishing Fuzhou City into a cultural tourism area in the hometown of Wang Anshi and making the city's cultural tourism a pillar industry for its economic growth.

1. To extend the industrial chain by creativity. Elements of Linchuan Culture can be combined with different aspects of tourism by creativity: the connotation of Linchuan Culture can be utilized to boost "dining, lodging, traffic, sightseeing, shopping and entertainment" and the ideology of Linchuan Culture can be applied to strengthen the competitiveness of Fuzhou tourism, so that visitors to Fuzhou will choose to stay longer instead of just taking one-day tour, consequently extending the industrial chain of Fuzhou's cultural tourism. Thus, the extensive way of tourism development that solely relies on the income of admission tickets can be shaken off, with the path of all-round tourism taken. Therefore, creativity should be exerted to combine Linchuan Culture with the elements of traditional Chinese opera, education, food, healthcare, urban construction and goods, so that tourists can go to Fuzhou for not only sightseeing but study, opera watching and shopping, thus achieving the overall appreciation of the industrial system of cultural tourism in Fuzhou. With the planning of Fuzhou Cultural Tourism Creative Industry Garden, it can be designed to consist of functional areas like Wang Anshi Cultural Tourism Theme Park, Fuzhou Folk Custom Park, Fuzhou Intangible Cultural Heritage Park, Tang Xianzu Opera, Film and TV Culture City, Fuzhou Handicraft Processing Experience Area, Fuzhou Education Culture Industrial Park, Fuzhou Oil Painting and Ceramic Artists Creation Center and Fuzhou Traditional Chinese Medicine Healthcare Center. Fuzhou Cultural Tourism Creativity Industry Garden must stick to the principle of presenting creativity by science and technology, expressing culture by creative thoughts and boosting tourism by cultural ideas, thus establishing Fuzhou Cultural Creative Industry Garden into the cradle of cultural creativity in Fuzhou and resort of relaxation and vacation, thus making it a multi-functional cultural tourism base that integrates culture, travel, entertainment, relaxation, science and technology and ecological harmony.

2. To lift tourism marketing and publicity. First, the idea of integrated marketing and publicity of cultural tourism in Fuzhou should be established. Cultural tourism in Fuzhou must integrate all means of marketing and publicity, be oriented to developing tourism brands, and ensure cultural tourism in Fuzhou a favorable reputation and image in the society. By combining tourism publicity of Fuzhou with publicity of Fuzhou City, combining promoting of Fuzhou tourism outward with taking in media for coverage, and combining publicity of the cultural tourism image of Fuzhou with 
publicity of tourist products, effective communication of Fuzhou City and the brands of scenic spots of cultural tourism in Fuzhou can be achieved.

Second, the idea of marketing and publicity of cultural tourism brands in Fuzhou should be built. The brand is a guarantee for quality services and products and for safe and reliable products of tourists. Enjoying high reputation and popularity, a brand can help attract tourists' attention and bring about favorable social and economic benefits. Therefore, establishing brands must an important part of cultural tourism development in Fuzhou. Brands must work hard on the striking characteristics of cultural tourism products in Fuzhou and enhance the service, grade and strength of cultural tourism products in the city.

Last but not the least, cultural tourism performances should be strongly supported. Tourism performance is drawing wider and wider attention from governments at all levels due to its irreplaceable role in attracting tourists, highlighting cultural connotation of a scenic area, promoting tourism brands and driving local economy [1]. For instance, the large-scale live-action performance "Impression Liu Sanjie the Great Singer" staged in Guilin innovated in combining the elements of Liu's folk songs, national custom and fishing boats on Lijiang River by four series of "theme colors" of red, white, silver and yellow. Since its inauguration in 2004, more than 5,800 sessions had been put on by Oct. 2016, attracting audiences as many as over 13 million [2]. Developing cultural tourism performance must be centered at presenting the folk custom of Fuzhou and connotation of Linchuan Culture, dependent on tourist areas and spots in Fuzhou, and aimed at shaping cultural tourism brands in Fuzhou, so as to meet tourists' need of spiritual enjoyment.

3. To enrich and enhance tourism products, limelight characteristics and foster quality products. Cultural tourism in Fuzhou should be rid of the pattern of monotonous products and the situation of having sightseeing the major product and low-level development; development of cultural tourism products in Fuzhou should be strengthened according to tourists' consumption demand and the features and law of developing cultural tourism products. While enhancing development of material culture tourism like food culture, architectural culture and ancient village culture, development of intangible cultural heritage tourism should be promoted. On the one hand, tourism development of folk custom in Fuzhou should be promoted; on the other, development of Fuzhou culture and art characterized by Fuzhou tea-picking opera and exorcising dance must be furthered. Monotonous development of sightseeing tourism products should be transformed into experiencing, entertaining, sightseeing and relaxing tourism products in order to enhance the experience and joy of tourists. Integration of tourism into the industries of cartoon, sports, convention and exhibition, film and TV and cultural creativity should be stressed to help tackle the difficulties in the expression of cultural tourism; development of cultural tourism commodities in Fuzhou should be heightened, support in talents, funds and policies should be offered, and tourism products of Fuzhou cultural characteristics should be developed, so that tourists in Fuzhou can not only have fun in views but get tourist commodities of Fuzhou characteristics.

Features should be highlighted and quality products should be fostered to enhance the quality of cultural tourism products in Fuzhou. Supported by Fuzhou characteristics and representative tourist resources, featured tourist routes, scenic areas and spots and tourist commodities of Fuzhou culture should be developed to increase the value and quality of cultural tourism products in Fuzhou and enhance their attraction. Priorities should be set to focus talents, materials and funds on fostering quality tourist products to fully display the connotation of Fuzhou Culture, present the essence of Fuzhou Culture, create quality products of Fuzhou cultural tourism and enhance the cultural connotation and value of Fuzhou cultural tourism products, so that the market competitiveness of Fuzhou cultural tourism products can be raised.

\section{References:}

[1] Song Yun and She Yu. Tourism Performance: A new paradigm of tourism marketing [J]. Jiangxi Social Sciences, 2011(12):221-224. 
[2] Meng Ping. Large-scale Live-action Performance: Feast of Tourism and Culture [N]. China Tourism News, 2005-07-11. 